\title{
ABSENSI QR CODE BERBASIS e-CONFIRMATION (BOT TELEGRAM) DAN E-NOTIFICATION DENGAN TEKNOLOGI GOOGLE ACCESS
}

\author{
M.Fadhilur Rahman¹, Moh. Ainol Yaqin² \\ Teknik Informatika, Fakultas Teknik \\ Universitas Nurul Jadid, Paiton Probolinggo, Indonesia \\ e-mail : ${ }^{1}$ fadilurrahman88@gmail.com, ${ }^{2}$ ainolyaqin09@gmail.com \\ Diterima: 18 April 2019. Disetujui : 12 Juni 2019. Dipublikasikan : 30 Juni 2019 \\ (C)2019 -TESJ Fakultas Teknik Universitas Maarif Hasyim Latif. Ini adalah artikel dengan \\ akses terbuka di bawah lisensi CC BY 4.0 (https://creativecommons.org/licenses/by/4.0/)
}

\section{ABSTRAK}

\begin{abstract}
Absensi dalam pendidikan sangat penting untuk mengetahui kehadiran dan ketidakhadiran baik itu guru dan siswa dan sebagai tolok ukur kedisiplinan guru dan murid. Absensi QR code merupakan ide kreatif untuk ramah lingkungan atau paperless, dimana teknologi tersebut berbasis e-Notification dan eConfirmation yang pemberitahuannya real time dan menggunakan teknologi yang sedang naik daun yaitu bot telegram. Bukan itu saja, penerapan Google access seperti Google form yang digunakan inputan data absensi dan Google Spread Sheet sebagai penyimpan data atau database, pelaporan nya mudah untuk dikelola lagi, karena pada dasarnya Google Spread Sheet atau Excel cuman online, tentunya keuntungan nya dari penggunaan tersebut adalah free atau tanpa biaya hanya bermodalkan email dari Google, tidak usah beli hosting dan domain. Sehingga proses kontroling dari pimpinan dapat terlaksana dengan baik, pihak pimpinan dapat mengetahui siswa, gurunya hadir dan tidak hadirnya, jam masuk kelas, materi yang disampaikan dan catatan harian secara real time. Dan target perencanaan pendidikan tercapai dengan maksimal.
\end{abstract}

Kata kunci: e-confirmation, e-notification, google access, qr code

\section{PENDAHULUAN}

Pendidikan adalah kebajikan manusia yang esensial, kebutuhan masyarakat, dasar kehidupan yang baik dan tanda kebebasan. Pendidikan itu penting untuk integrasi entitas yang terpisah (Bhardwaj, 2016). Hal tersebut menandai bahwa pendidikan esensial manusia yang menentukan arah kebijakan dalam semua sisi kehidupan manusia baik itu sosial, hukum, kebudayaan dan banyak lainnya. Pendidikan mengajarkan banyak hal, mengajarkan tata krama, aturan dan peraturan hidup dan lain-lainnya. Serta pada dasarnya setiap manusia membutuhkan pendidikan untuk berinteraksi dengan perubahan zaman dan dapat mengangkat derajat manusia baik hubungan antara manusia ataupun dengan sang Khalik-nya. Dari itu semua pendidikan harus disampaikan dengan benar dan baik. Terdapat dua komponen pendidikan yang harus ada yaitu guru sebagai fasilitator, pengarah atau bahkan pemberi ilmu pada proses pendidikan. Dan siswa sebagai penerima ilmu, yang menjadi objek, sasaran transfer of knowledge (ilmu) oleh guru. Sistem pendidikan akademik Rumania menerapkan pendidikan yang berpusat pada siswa. Tujuannya adalah untuk memfasilitasi kesadaran dan juga untuk menawarkan panduan, model implementasi aktual dari pendidikan berpusat pada siswa (Roșca, 2015). Akan tetapi hemat kami, kedua komponen tersebut baik guru dan murid saling membutuhkan, guru sebagai penggerak kehidupan pendidikan di kelas dan siswa sebagai objek yang harus aktif dalam proses menjadi jati diri atau ilmu dari guru. Dalam proses pendidikan adalah diharapkan bahwa peserta didik secara aktif mengembangkan potensi untuk mereka memiliki kekuatan spiritual agama, pengendalian diri, kepribadian, kecerdasan, karakter dan keterampilan untuk diri mereka sendiri, masyarakat, bangsa dan negara. Pembentukan karakter atau Pikiran atau kepribadian sebagai salah satu tujuan pendidikan sangat penting dan bahkan yang paling penting karena terkait dengan output dari siswa (Sudarsana, 2016). Akan tercapai jika antara guru dan murid dapat melaksanakan tugas masing masing komponen, contoh guru melakukan proses pembelajaran yang benar dimana sesuai dengan target rancangan pembelajaran dan memberikan tindakan-tindakan yang baik salah satunya adalah kedisiplinan. Siswa menyimak pembelajaran dengan seksama dan melakukan kegiatan-kegiatan pembelajaran salah satunya rajin dan giat belajar. Agar lebih efisien 
maka diperlukan Teknologi pendidikan, Teknologi pendidikan adalah sistematika dan proses terorganisir menerapkan teknologi modern untuk meningkatkan kualitas pendidikan (Lazar, 2015). Maka dari itu, dibangun dan dirancang suatu sistem agar dapat mengontrol proses pembelajaran dari absensi, kegiatan pembelajaran yang secara real time terlaporkan ke pimpnan sekolah dengan judul 'sistem Absensi QR Code berbasis eConfirmation (bot telegram) dan e-Notification dengan teknologi Google Access'. Arah pengembangan aplikasi tersebut bertujuan untuk meningkatkan kerajinan siswa, dengan melakukan tindakan jika terdapat siswa yang tidak masuk dan diproses sebagaimana mestinya.

\section{Penelitian Terkait}

Penelitian terkait pertama Al-Khalifa (AlKhalifa, 2008) dimana sistem berbasis barcode untuk membantu tunanetra dan orang buta mengidentifikasi benda di lingkungan diperkenalkan. Sistem didasarkan pada ide penggunaan kode QR (barcode dua dimensi) yang ditempelkan sebuah objek dan dipindai menggunakan telepon kamera yang dilengkapi dengan perangkat lunak pembaca QR. Pembaca menerjemahkan kode batang ke URL dan mengarahkan browser ponsel ke ambil file audio dari Web yang berisi deskripsi verbal objek.

Penelitian terkait berikutnya oleh Qurotul Aini dkk (Aini, Rahardja, \& Fatillah, 2018). Pemanfaatannya QRCode untuk abensi yang ada pada ruang Laboratorium, untuk memberikan penilaian kepada asisten lab atau Pensil (Penilaian Asisten Lab). Dimana akan terkoneksi dengan website pensil.raharja.ac.id. Program yang digunakan berbasis php native.

Penelitian terkait ketiga oleh Muhamat Al Satrio dkk (Satrio, Abdillah, \& Syazili, 2017). Dengan pemanfaatkan teknologi QR Code, data siswa bisa disimpan dalam bentuk gambar $Q R$ Code yang akan ditempel / dilekatkan pada Kartu Identitas Mahasiswa (KTM). Kemudian proses kehadiran dilakukan melalui kehadiran aplikasi QR Code smartphone yang telah terpasang (dipasang) oleh semua dosen. Dan akhirnya, data dikirim untuk kehadiran informasi media Universitas Bina Darma melalui internet.

Pada ketiga penelitian terkait di atas memanfaatkan teknologi QRcode untuk mendapatkan saja, dari tempat tertentu, tanpa adanya pemberitahuan secara langsung, jadi proses kontrolnya tidak langsung terjadi, masih ada waktu selang. Sehingga kemungkinan terjadi manipulasi data yang dikirim. Jika dibandingkan dengan penelitian saat ini, tentunya lebih unggul aplikasi ini, karena sistem ini memanfaatkan bot telegram dalam mengirimkan data ke pimpinan dan secara real time, dan e-Notification untuk yang melakukan pengabsenan yang mana terkirim ke email dan juga secara real time. Dan memanfaatkan media Google Access, hanya bermodal email dan free (tidak usah membeli hosting dan domain). Google Access yang digunakan yaitu Google Form untuk media tempat absensinya dan Google Spreadsheet sebagai database (penyimpanan data). Dari penggunakan teknologi tersebut pemanggilan QR Code-nya yang berbasis android menggunakan MIT App Inventor. Dengan kombinasi teknologi tersebut terbetuklah aplikasi yang memberikan kemudahan dalam membantu pimpinan mengkontrol guru dan siswanya.

\section{Absensi}

Absensi menurut Kamus Besar Bahasa Indonesia (KBBI) absensi adalah ketidakhadiran, akan tetapi kata absensi kebanyakan menjadi kehadiran dan ketidakhadiran. Jadi hemat kami tentang absensi adalah suatu pendataan tentang kehadiran atau ketidakhadiran. Jika dalam dunia akademik terdapat 4 yang tercantum dalam absensi tersebut, yaitu : masuk, sakit (s), ijin(i) dan alpa (a). Supaya absensi terkontrol dengan baik dan tepat maka dibuatlah aplikasi QR code, dengan tujuan memberikan kemudahan pada pihak sekolah mengetahui siswa yang tidak masuk dan cepat dan tepat sasaran dalam melakukan tindakan sesuai prosedur.

\section{Qr Code}

Qr Code (quick response) (Ashford, 2010), sejenis barcode, merupakan terobosan di Amerika Serikat. Kode QR adalah barcode matriks yang dapat dibaca oleh ponsel pintar dan ponsel dengan kamera. Kadang-kadang disebut sebagai Kode 2d, kode batang $2 \mathrm{~d}$, atau kode seluler. Di kebanyakan ponsel harus mengunduh aplikasi gratis untuk membaca kode QR, meskipun beberapa ponsel sudah diprainstall. Kecanggihan sederhana dan mudah jika dibandingkan dengan sistem ada finger print, yang itu masih menggunakan alat dan kurang fleksibel penggunaannya. Sistem kerjanya pada aplikasi absensi QRcode sebagai wadah url yang akan mengarahkan ke google form pada setiap kelas yang ter-koneksi dengan bot telegram.

\section{e-Confirmation dan e-Notification}

e-Notification dan e-Confirmation dua hal yang memiliki sifat yang sama yaitu pemberitahuan dengan media elektronik, akan tetap memiliki arah yang berbeda. Jika eNotification pemberitahuan untuk subjek atau yang melakukan inputan dari materi, mata pelajaran, jam pelajaran, catatan guru dan keterangan masuk dan tidak masuknya siswa, contoh ini ada pada guru, setelah melakukan absensi akan mendapatkan kiriman melalu guru, bahwasanya sudah absen telah diterima dan terdapat ucapan 
terima dari pihak sekolah. Pada e-Confirmation pemberitahuan bahwa guru sudah melakukan absensi guru, siswa dan pemberitahuan kegiatan belajar mengajar melalui media bot telegram. Proses e-Notification dan e-Confirmation bersifat real time, arti setiap terjadi input secara otomatis melakukan pemberitahuan.

\section{Google Access}

Google Access merupakan istilah yang dibuat sendiri boleh peneliti, dengan tujuan mempermudah istilah yang digunakan. Google accces media yang terdapat di Google dan penggunaannya free (bebas biaya) cukup berbekalkan email dari Gmail. Pemanfaatan Google-nya yang akan digunakan adalah Google form sebagai media inputan dan Google Spread Sheet sebagai database penyimpanan atau database. Jadi databasenya akan berubah MS Excel, sehingga memberikan kemudahan dalam pengelolaan data tersebut. Pengkodean terdapat di code-script pada bagian Google Spread Sheet, dari e-Notification, e-Confirmation dan koneksi antar Google Spread Sheet dengan bot telegram yang mencantumkan API token dari telegram.

\section{MIT App Inventor}

MIT App Inventor adalah bahasa blok visual, yang memungkinkan pemula dan non-programer untuk membuat aplikasi untuk ponsel dan tablet (Wolber, Abelson, \& Friedman, 2015). Sistem pengkodingan dengan cara drag and drop atau blok tinggal ditarik sesuai dengan keinginan tanpa mengetik. MIT APP Inventor untuk membuat pembaca QRcode yang dikirimkan dengan tujuannya penampilkam form absensinya.

\section{METODE PENELITIAN}

Metode penelitan yang digunakan untuk membangun sistem Absensi QR Code berbasis eConfirmation (bot telegram) dan e-Notification dengan teknologi Google Access, sebagaimana pada Gambar 1.

\section{Penelitian Awal}

Penelitian awal akan dilakukan oleh ketua dan anggota penelitian di MA Nurul Qadim yang terletak desa Kalikajar Kulon kecamatan Paiton Kabupaten Problinggo dengan wakil kepala sekolah yaitu bapak Yasin, dengan beliau akan melakukan wawancara dan observasi. Dari kedua kegiatan tersebut, wawancara telah dilakukan dan hasil wawancara tersebut ada beberap temuan yang membuktikan bahwa sulitnya mengidentifikasi kedisiplinan guru dan murid, serta target yang sebelumnya direncanakan terkadang tidak maksimal. Maka aplikasi ini akan membantu dalam mengontrol guru dan murid

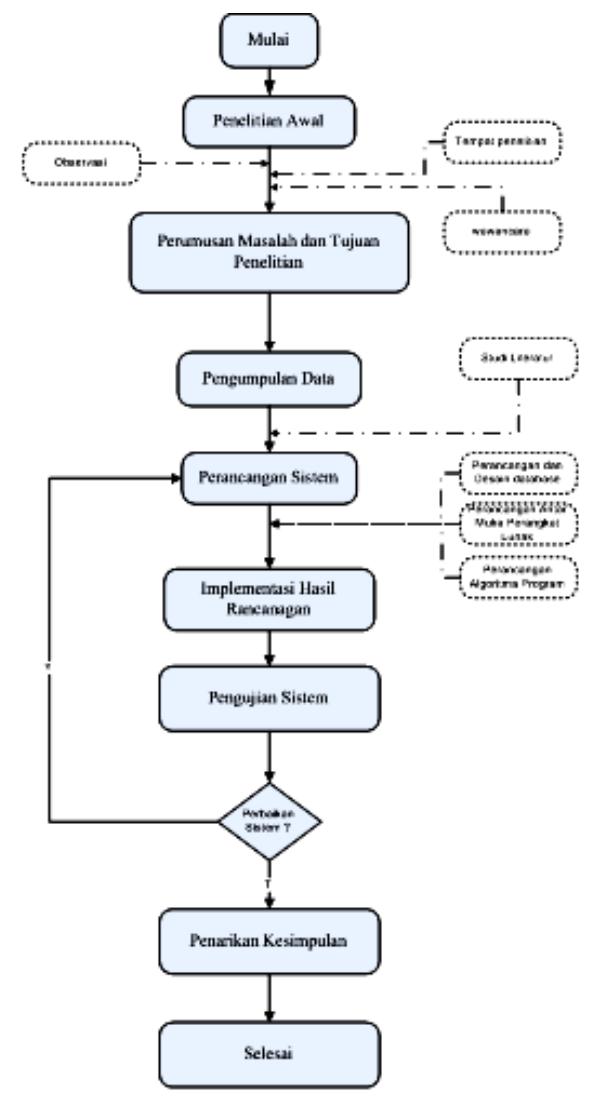

Gambar 1. Tahapan Metode Penelitian

\section{Perumusan Masalah dan Tujuan Penelitian}

Kegiatan ini dilakukan oleh ketua dan anggota penelitian. Dari hasil wawancara dan obsevasi pada penelitian awal, ada beberapa permasalahan yang harus diselesaikan dengan sistem yang terorganisir dengan baik dan terencana. Proses yang ada pada saat ini absensi masih manual menggunakan kertas dan sulit mengetahui materi yang disampaikan, karena kebanyakan terdapat manipulasi data. Dan tidak dapat mengidentifikasi keterlambatan guru dan siswa, serta karena menggunakan kertas sehingga rawan rusak dan hilang serta masih harus kerja dua kali karena ada perpindahan dari kerta ke komputer. Tentunya dengan adanya sistem tersebut dapat memberikan kemudahaan dalam kontrol absensi, keterlambatan, materi pembelajaran, keterangan kehadiran siswa dan catatan guru, hal-hal tersebut terkirim real time ke Pimpinan sekolah dengan teknologi bot telegram.

\section{Pengumpulan Data.}

Pengumpulan data dilakukan oleh ketua dan anggota penelitian. Pengumpulan data pada bagian ini merupakan tindak lanjut dari wawancara dan observasi pada penelitian awal, yang ditunjang dengan studi literatur. Studi literatur merupakan 
kegiatan yang dilakukan untuk mempelajari dan memahami Absensi QR Code berbasis $\mathrm{e}-$ Confirmation (bot telegram) dan e-Notification dengan teknologi Google Access, pengembangan sistem informasi, MIT App Inventor sebagai pembaca QR-code-nya, Google form untuk inputannya, Google Spread Sheet sebagai penyimpanan data atau databasenya dan menggunakan teknologi bot telegram sebagai pengiriman data secara real time.

\section{Perancangan Sistem}

Proses perancangan Sistem dilakukan oleh ketua penelitian. Perancangan sistem yang dimaksud adalah perancangan sistem memahami Absensi QR Code berbasis e-Confirmation (bot telegram) dan e-Notification dengan teknologi Google Access secara konseptual. Perancangan sistem yang dimaksud meliputi tiga aspek penting yaitu (1) perancangan database sebagai basis penambangan data; (2) perancangan antar muka perangkat lunak yang dibangun dan (3) perancangan algoritma program.

\section{Implementasi Rancangan.}

Implementasi Rancangan dilakukan oleh ketua penelitian. Tahapan ini adalah membuat aplikasi tersebut dan pengkodingan aplikasi pada Google Spread Sheet pada bagian script-code, yang sesuai dengan perancangan sistem. Sehingga terbangun sebuah aplikasi untuk menyelesaikan masalah dalam penelitian ini.

\section{Pengujian Sistem}

Ketua dan anggota penelitian melakukan kegiatan ini. Menguji aplikasi dengan cara uji coba sistem. Jika sesuai maka dilanjutkan jika tidak maka kembali perancangan sistem.

\section{Penarikan Kesimpulan}

Penarikan kesimpulan dilakukan oleh ketua dan anggota penelitian. Kesimpulan didapat dari aplikasi dan proses penelitian yang dilakukan dan tidak lanjut dari penelitian akan menjadi saran yang akan lebih dikembangkan lagi oleh penelitian.

\section{HASIL DAN PEMBAHASAN}

Hasil akhir dari penelitian ini adalah Absensi QR Code berbasis e-Confirmation (bot telegram) dan e-Notification dengan teknologi Google Access. Targetnya aplikasi yang menggunakan Android. Dalam android tersebut merupakan kombinasi dari Google form (sebagai form setiap kelasnya), Google Sheets (sebagai database dan memanfaatkan email untuk konfirmasi bahwanya guru tersebut sudah melakukan absensi), Bot Telegram (sebagai notifikasi yang pada kepala sekolah bahwasanya guru sudah melakukan absensi) dan Aplikasi Android menggunkan MIT App Inventor yang menerapkan sistem Qr Code-nya (sebagai scanner atau membaca Qr code-nya), semua tool di atas saling berintegrasi. Jika dibuat alur sistemnya seperi pada Gambar2.

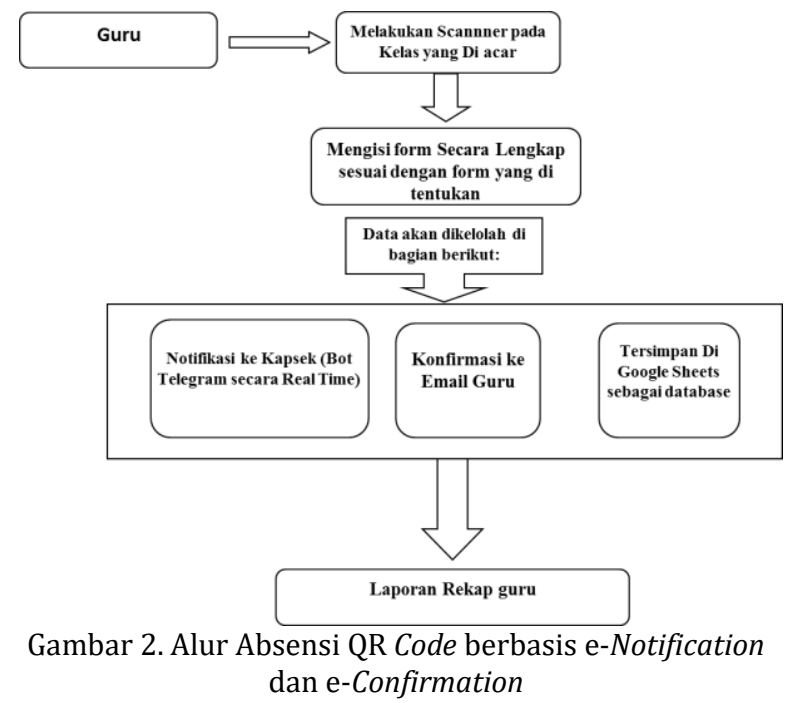

Alur tersebut sangat sederhana, sehingga memberikan kemudahan bagi guru dalam melakukan absensi. Rekapnya dihitung per jam atau setiap pergantian jam, untuk mendetailkan guru yang masuk pada setiap jamnya. Terlebih dahulu pasang atau install APK-nya, seperti Gambar 3 .

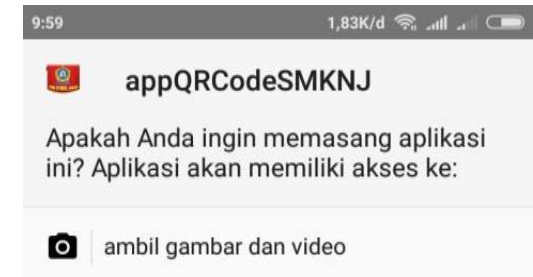

BATAL PASANG

Gambar 3. Instalasi APK Absensi QR Code

Hasil dari instalasi APK-nya berupa icon di samartphone android-nya, tinggal diklik kemudian dijalankan, seperti Gambar 4. 


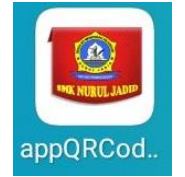

Gambar 4. Hasil Install aplikasi Absensi QRCode

Logo di atas tidak permanen bisa diubah sesuai dengan logo sekolah yang membutuhkan aplikasi QR code ini, sekedar informasi, membuatan aplikasi ini menggunakan MIT App Inventor, dimana harus online ketika pembuatannya. Hasil jika diklik Gambar 5.

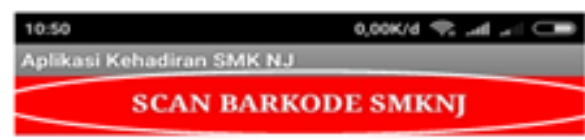

Gambar 5. Aplikasi Absensi QR Code

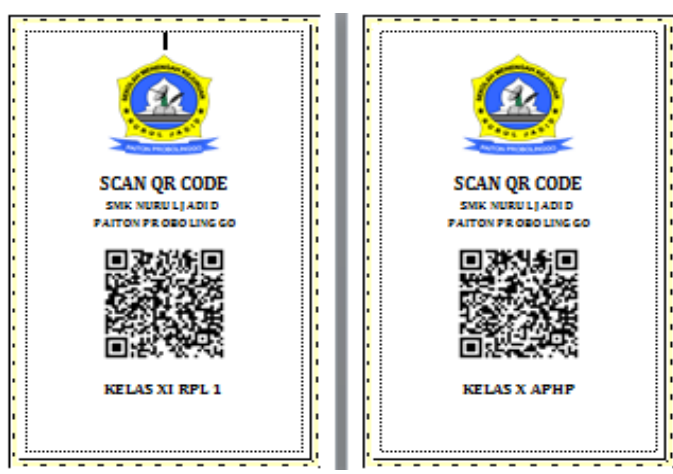

Gambar 6. Contoh QRCode yang ada di kelas

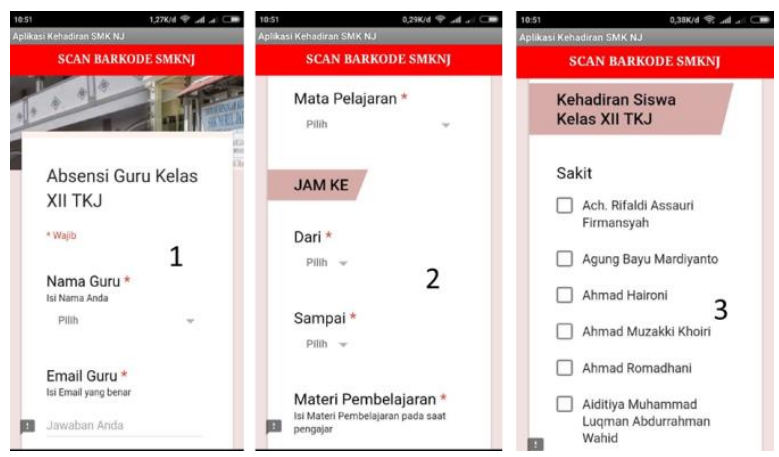

Gambar 7. Tampilan Setelah di QRCode dengan aplikasi (Google Form)

Jika lingkaran di atas diklik maka akan jalan scanner kemudian diarahkan pada Qr-Code yang ada pada kelas, Gambar 6 contoh QR Code yang ada pada kelas.

QR code di atas akan ditempel pada setiap kelas, jadi ketika guru sebelum melakukan pembelajaran guru melakukan scanning dengan Aplikasi Absensi Qr code, dan akan tampil form yang sesuai dengan kelas yang dipindai. Hasilnya sebagai seperti pada Gambar 7.

Tampilan Gambar 7 sebenarnya memanjang ke bawah sesuai dengan urutannya, isian dari datanya dari nama, mata pelajaran sampai absensi siswa. Jadi aplikasi ini, ada dua yang sudah tertangani yaitu absensi guru dan siswa. Jika sudah melakukan absensi maka guru akan dapat mendapat email konfirmasi seperti Gambar 8.

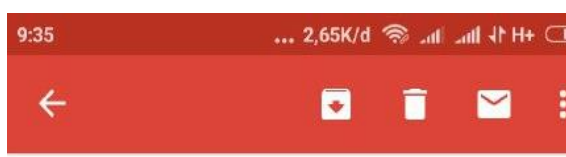

Email Konfirmasi, Kalau sudah melakukan Absensi Kotak Masuk

A Absensi Kehadiran Guru ke saya 09.35 Tampilkan detailnya

Hai Moh. Ainol Yaqin, M. Kom

Terima kasih anda telah melakukan absensi mengajar mata pelajaran Pemrograman Web dan Perangkat Bergerak dari jam 1 sampai jam 3.

Semoga amalnya diterima oleh Allah SWT

Hormat Kami, Kepala SMK Nurul Jadid

ABDUL MANAF FIRDAUS, M.Pd.

Gambar 8. e-konfirmasi guru

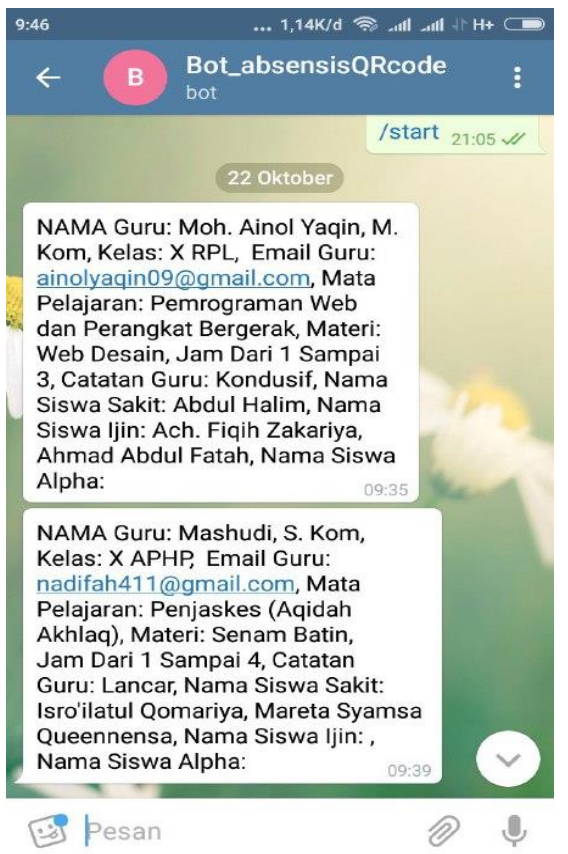

Gambar 9. e-Notification real time ke pimpinan 
Dan notifikasi ke pimpinan atau yang sebelumnya sudah terdaftarkan Chat ID-nya ke sistem seperti Gambar 9.

Laporan absensinya akan berbentuk excel tapi e-Excel atau google sheets. Hasilnya seperti Gambar 10.

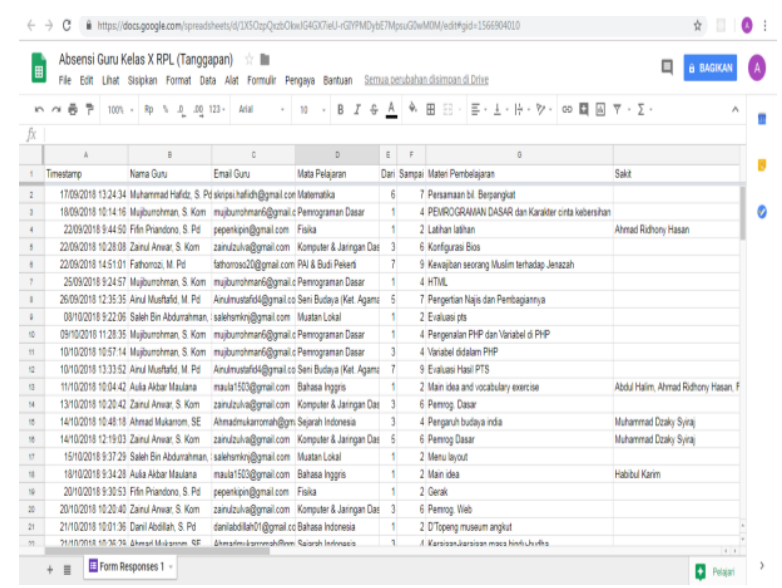

Gambar 10. Laporan Absensi via Google Sheets (online)

Proses rekap dikelola oleh bagian TU dan bendahara untuk menentukan gaji pada setiap guru dilihat dari jumlah masuk perjamnya. Bagi siswa yang kehadirannya di bawah $75 \%$ dilakukan oleh bagian BK untuk melakukan bimbingan agar lebih rajin dan mendapatkan ilmu yang bermanfaat bagi Bangsa dan Negara.

\section{PENUTUP}

Kesimpulan dari penelitian ini memberikan kemudahan bagi pihak guru melakukan absensi terdapat guru. Bagi sekolah dapat melacak kegiatan-kegiatan guru dalam kelas dari materi pembelajaran, rekapitulasi kehadiran guru dan kegiatan KBM di kelas. Kepala Sekolah dapat mengontrol kehadiran guru secara real time tanpa harus datang ke sekolah. Saran penelitian ini lebih dikembangkan lagi dengan menggunakan aplikasi android yang sudah GPS (Global Positioning System), agar tidak usah pengawasan dari petugas piket, akan tetapi hal seperti itu akan mengurangi SDM (sumber daya manusia) sehingga akan berdampak pada pengangguran, akan tetapi hal itu menjadi kebijakan sekolah terkait.

\section{UCAPAN TERIMA KASIH}

Ucapan terimakasih ini disampaikan kepada Rektor UNUJA (Univeritas Nurul Jadid), Dekan Fakultas Tekin UNUJA, Ka. Prodi Informatika UNUJA dan rekan seperjuangan, Dosen Informatika Univeritas Nurul Jadid yang telah memberikan dukungan Moril dan Moral sehingga artikel ini terselesaikan dengan baik.

\section{DAFTAR PUSTAKA}

Aini, Q., Rahardja, U., \& Fatillah, A. (2018). Penerapan Qrcode Sebagai Media Pelayanan Untuk Absensi Pada Website Berbasis Php Native. Sisfotenika, 8(1), 47-56.

Al-Khalifa, H. S. (2008). Utilizing QR code and mobile phones for blinds and visually impaired people. Lecture Notes in Computer Science (Including Subseries Lecture Notes in Artificial Intelligence and Lecture Notes in Bioinformatics), 5105 LNCS, 1065-1069. https://doi.org/10.1007/978-3-540-705406_159

Ashford, R. (2010). QR codes and academic libraries: Reaching mobile users. George Fox University Libraries.

Bhardwaj, A. (2016). Importance of Education in Human Life: a Holistic Approach. International Journal of Science and Consciousness, 2(2), 23-28.

Lazar, S. (2015). The importance of educational technology in teaching. International Journal of Cognitive Research in Science, Engineering and Education, 3(1).

Roșca, R. D. (2015). IMPLEMENTATION MODEL OF THE STUDENT CENTRED EDUCATION IN A UNIVERSITY IN ROMANIA. 4(1), 99-104.

Satrio, M. Al, Abdillah, L. A., \& Syazili, A. (2017). Aplikasi Presensi Mahasiswa dengan Menggunakan QR Code Berbasis Android pada Universitas Bina Darma.

Sudarsana, I. K. (2016). The Importance of Morals Teaching in Shaping the Students' characters in School. DHARMA ACARYA FACULTY INTERNATIONAL SEMINAR, 1, 306-315.

Wolber, D., Abelson, H., \& Friedman, M. (2015). Democratizing computing with app inventor. GetMobile: Mobile Computing and Communications, 18(4), 53-58. 